\title{
Behavioural and psychological symptoms of dementia in patients with Alzheimer's disease and family caregiver burden: a path analysis
}

Bokyoung Kim', Gie Ok Noh²* and Kyunghee $\mathrm{Kim}^{3}$

\begin{abstract}
Background: Studies reported the relationship between behavioural and psychological symptoms of dementia (BPSD), cognitive function, caregiver burden, and therapeutic effects. However, the causal relationship between BPSD in community-dwelling patients with Alzheimer's disease (AD) and caregiver burden is yet to be established. This study aimed to classify BPSD in patients with AD and identify the relationship between BPSD and the factors affecting family caregiver burden.

Methods: Path analysis was conducted at a neurology outpatient clinic of a tertiary general hospital in South Korea. The medical records of 170 patients, aged $\geq 50$ years, diagnosed with or suspected for AD were retrospectively reviewed. We investigated cognitive function (Korean version of the Mini-Mental-State Exam), dementia stages (Korean version of the Expanded Clinical Dementia Rating scale), depression (Short-form Geriatric Depression ScaleKorea), activities of daily living (ADL; Korean version of the Barthel Activities of Daily Living index), instrumental activities of daily living (IADL; Seoul-Instrumental Activities of Daily Living), and BPSD and caregiver burden (Korean Neuropsychiatric Inventory). Considering the characteristic features of BPSD with various symptoms, BPSD was classified using factor analysis. Factor extraction was performed using principal component analysis, followed by Varimax factor rotation.

Results: Mean total BPSD score was $17.66 \pm 20.67$, and the mean score for family caregiver burden was $9.65 \pm 11.12$. Symptom cluster-1 (hyperactivity symptoms) included disinhibition, irritability, and agitation/aggression. Symptom cluster-2 (psychosis symptoms) included hallucinations, anxiety, elation/euphoria, delusions, and depression/dysphoria. Symptom cluster-3 (physical behaviour symptoms) included appetite and eating abnormalities, apathy/indifference, aberrant motor behaviour, sleep, and night-time behaviour disturbances. Dementia stages, ADL, and IADL had indirect effects on family caregiver burden through hyperactivity, psychosis, and physical behaviour symptoms, indicating that BPSD exerted a complete mediating effect.

(Continued on next page)
\end{abstract}

\footnotetext{
* Correspondence: nkorn91@gmail.com

${ }^{2}$ Department of Nursing, Konyang University, 158 Gwanjeodong-ro, Seo-gu, Daejeon 35365, South Korea

Full list of author information is available at the end of the article
}

(c) The Author(s). 2021 Open Access This article is licensed under a Creative Commons Attribution 4.0 International License, which permits use, sharing, adaptation, distribution and reproduction in any medium or format, as long as you give appropriate credit to the original author(s) and the source, provide a link to the Creative Commons licence, and indicate if changes were made. The images or other third party material in this article are included in the article's Creative Commons licence, unless indicated otherwise in a credit line to the material. If material is not included in the article's Creative Commons licence and your intended use is not permitted by statutory regulation or exceeds the permitted use, you will need to obtain permission directly from the copyright holder. To view a copy of this licence, visit http://creativecommons.org/licenses/by/4.0/ The Creative Commons Public Domain Dedication waiver (http://creativecommons.org/publicdomain/zero/1.0/) applies to the data made available in this article, unless otherwise stated in a credit line to the data. 
(Continued from previous page)

Conclusions: Unlike previous studies, we classified BPSD symptoms into similar symptom clusters to evaluate its effect on caregiver burden, rather than collectively investigating the 12 symptoms of BPSD. As the dementia stage worsens, symptom clusters in BPSD serve as a medium between ADL and IADL degradation and for the increase in caregivers' burden. The development and implementation of therapeutic, nursing interventions, and policies focusing on dementia stages, ADL, and IADL, delaying and preventing BPSD can alleviate family caregivers' burden.

Keywords: Alzheimer's disease, Behavioural and psychological symptoms, Burden, Dementia, Family caregivers, Neurology, Path analysis, Symptom cluster

\section{Background}

The prevalence of dementia in the elderly in South Korea was reported to be $10.7 \%$, and the number of patients with dementia is estimated to exceed 3 million by 2050 [1]. Alzheimer's disease (AD) is the most common type of dementia, accounting for $60-70 \%$ of all patients with dementia [2].

The prevalence of non-cognitive behavioural and psychological symptoms of dementia (BPSD) in patients with $\mathrm{AD}$ is $56-98 \%$ in the community and up to $91-96 \%$ in hospitals or long-term care facilities [3]. BPSD exacerbates cognitive decline and physical dysfunction in patients with AD [4] and imposes a great burden and stress on the caregivers of patients with dementia $[3,5]$.

In particular, family caregivers of patients with dementia were found to be associated with social isolation, physical health deterioration, and psychological disorders such as depression. Likewise, these people were also found to experience financial difficulties [6]. Owing to the prolonged disease course, the burden on family caregivers has led to emerging social problems such as conflicts within the family, deterioration of the patient-caregiver relationship, patient abuse, and suicides. Therefore, studies on family caregiver burden are warranted.

Factors related to caregiver burden as reported in previous research are cognitive function [5], stages of dementia [7], depression [7], activities of daily living (ADL) [8], instrumental activities of daily living (IADL) [9], and BPSD $[5,10]$. However, it is reported that cognitive function [11], disease progression [12], depression [11], ADL [11], and IADL [13] are related to BPSD. In addition, some studies have reported on the relationships between BPSD, cognitive function, caregiver burden, and therapeutic effects [14]. However, causal relationships between such factors have not yet been established. Furthermore, since caregiver burden and BPSD have been studied with a focus on a single symptom, BPSD expression characteristics have not been fully reflected. As BPSD manifests with the co-occurrence of various symptoms, a trend to investigate BPSD as symptom clusters or groups of related symptoms in a wide range [15] has been established. Previous studies have reported on the classification of the clusters of BPSD symptoms in patients with dementia [15-17].
Garre-Olmo et al. [16] classified BPSD into psychotic, emotional, and behavioural syndromes. In South Korea, a study reported on factor analyses of BPSD in patients with $\mathrm{AD}$ living in an institutional setting [18], and another study reported the effects of BPSD in elderly patients with dementia in nursing homes [5]. However, studies regarding the causal relationship between BPSD in communitydwelling patients with AD and caregiver burden have not yet been established. There is also a lack of research that classifies BPSD as symptom clusters to determine how each cluster affects caregiver burden and which clusters have the greatest impact on burden. If we determine which symptom cluster affects caregiver burden and which BPSD makes up these clusters, then the same treatment and nursing approach could be employed for these symptoms [15].

The present study aimed to (i) classify BPSD in patients with AD, (ii) identify the causal relationship between BPSD and the factors affecting family caregiver burden, and (iii) provide empirical data for the development of systematic therapeutic and nursing intervention programmes to address family caregiver burden.

\section{Methods \\ Study design}

A path analysis was designed to predict causal factors of BPSD in patients with AD and the corresponding burden of the family caregivers. The study is prepared in accordance with the STROBE guidelines and regulations.

\section{Use of the conceptual framework}

We constructed a framework based on previous reviews to identify the factors affecting burden among the family caregivers of patients with AD. These reviews found that the disease characteristics of patients with $\mathrm{AD}$, such as cognitive function [11], disease progression [12], depression [11], ADL [11], and IADL [13] as perceived by the caregivers, were related to BPSD. However, cognitive function [5], stages of dementia [7], depression [7], ADL [8], IADL [9], and BPSD [5, 10] were related to caregiver burden.

Based on these results, cognitive function, stages of dementia, depression, ADL, IADL, and BPSD were selected 
as the primary influencing factors of family caregiver burden. Figures 1 and 2 show the conceptual framework consisting of the paths in which these factors directly and indirectly, respectively, affect family caregiver burden through BPSD.

\section{Data collection and ethical considerations}

This study used the data retrospectively collected from the medical records of 170 patients with $\mathrm{AD}$ who visited the neurology outpatient clinic of a tertiary general hospital in South Korea between January 2011 and February 2016. The study was approved by the Institutional Review Board (IRB) Department of Chung-Ang University Hospital (approval No.: C20160791822) for ethical protection of the participants and for accessing their medical records, including the electronic medical records (EMR) of the respective patients. Governmentdesignated Clinical Research Center for Dementia (CRCD) caregiver questionnaires were completed by the family caregivers. The institutional review board waived the requirement of a written-informed consent from patients and caregivers because the data were historical and had already been collected for diagnostic and therapeutic purposes. The institution also determined that this study was eligible for an exempt status based on the exempt application stating that private data, such as those of patient hospital number, name, and family caregivers' contacts, will not be recorded. The original CRCD caregiver questionnaires were administered by the staff of the neurology outpatient department and stored in the laboratory of the neurology outpatient department. The EMR of the patients and CRCD caregiver questionnaires were viewed and recorded only in the laboratory to foster patient confidentiality. Serial numbers were assigned to each patient. Software files were stored in encrypted folders on computers with access only to the researcher.

Data on cognitive function, stages of dementia, depression, ADL, IADL, BPSD, and family caregivers' burden were collected from medical records including patients' EMR and CRCD caregiver questionnaires. A total of 170 questionnaires were analysed.

\section{Participants}

The participants in this study were patients who (i) were diagnosed with or suspected for AD, (ii) aged $\geq 50$ years, (iii) visited the neurology outpatient clinic of a tertiary hospital in South Korea, and (iv) whose family caregivers completed the CRCD questionnaires. In this study, the classification of $\mathrm{AD}$ (diagnosed or suspected) utilised diagnostic criteria of American Psychiatric Association DSM-IV standards, National Institute of Neurological and Communicative Disease and Stroke/Alzheimer's Disease and Related Disorders Association (NINCDSADRDA) $[19,20]$. In case there were multiple data for the same patient who visited our institution between January 2011 and February 2016, we used the recent data. The minimum number of samples required for factor analysis is $75-100$, wherein an excellent-level criterion is 0.98 , and the number of factors is 3 [21]. If the number of samples required for a path analysis is 100 or more, then it is deemed an appropriate sample size [22]. Therefore, the data of 170 subjects were appropriate for the analysis.

\section{Instruments}

\section{Cognitive function}

Cognitive function identified from the medical records was measured using the Korean version of the MiniMental State Examination (K-MMSE), which was translated into Korean by Kang et al. [23] based on the

\begin{tabular}{|c|c|c|}
\hline & $\begin{array}{l}\text { Behavioural and Psychological } \\
\text { Symptoms of Dementia(BPSD) } \\
\text { administered to } \\
\text { the patient's family caregivers } \\
\text { : delusions, hallucinations, agitation, } \\
\text { dysphoria, anxiety, apathy, irritability, } \\
\text { euphoria, disinhibition, aberrant motor }\end{array}$ & \\
\hline $\begin{array}{l}\text { Clinical characteristics of } \\
\text { Alzheimer's dementia patients }\end{array}$ & $\begin{array}{l}\text { disturbances, and appetite and eating } \\
\text { abnormalities }\end{array}$ & $\begin{array}{c}\text { Family caregivers of } \\
\text { Alzheimer's dementia patients }\end{array}$ \\
\hline Cognitive Function & Symptom cluster & \\
\hline Stages of Dementia & & \\
\hline Depression & Symptom cluster & Family caregivers burden \\
\hline Activities of Daily Living & & \\
\hline Instrumental Activities of Daily Living & Symptom cluster & \\
\hline
\end{tabular}




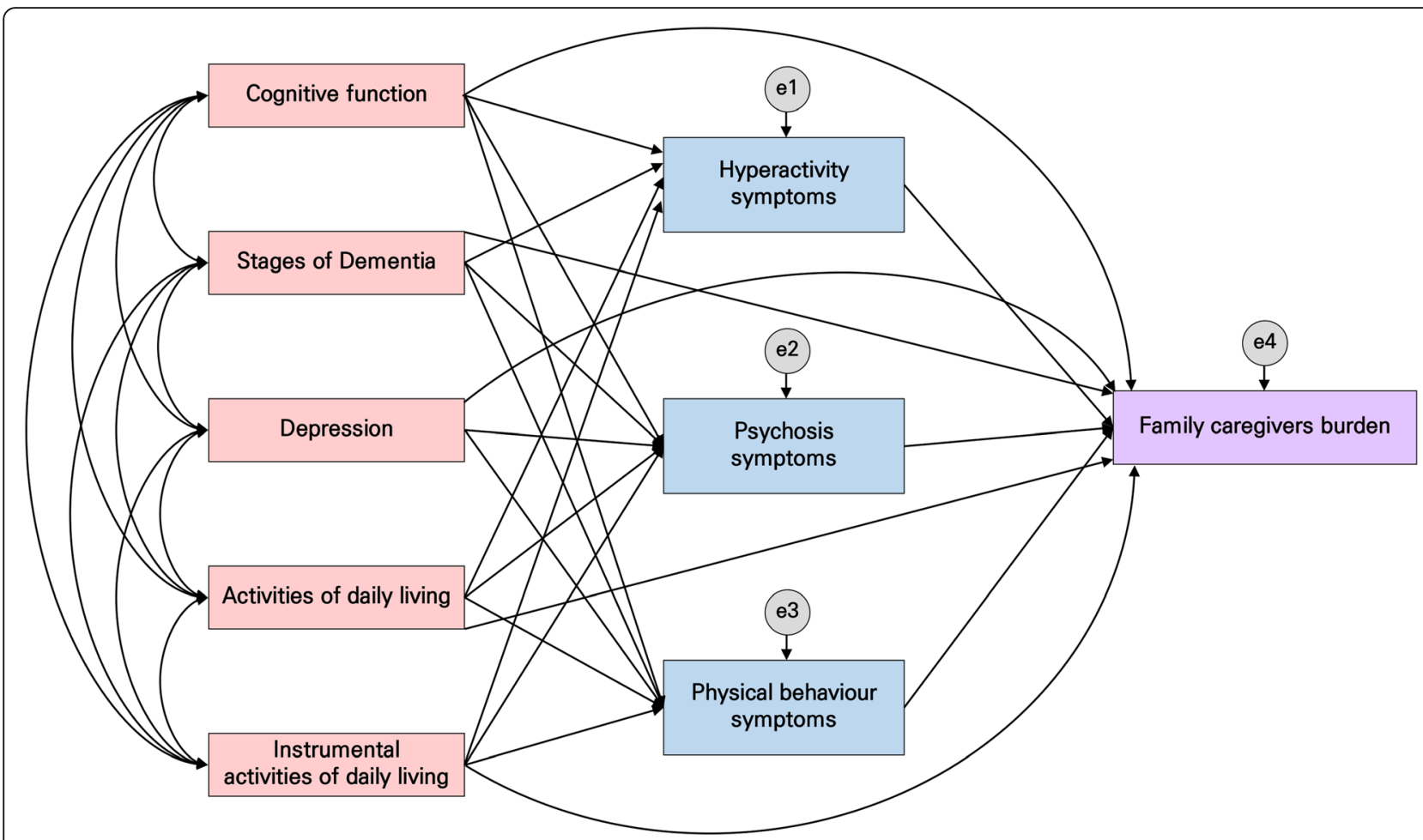

Fig. 2 Path diagram of the hypothetical model

original version by Folstein et al. [24] The K-MMSE consists of a total of 30 items regarding orientation for time, place, registration, attention and calculation, recall, language, and visual construction. Each item is scored as 1 point per factored answer. A lower score indicates more severe cognitive impairment; a score of $\geq 24$ is classified as non-cognitive impairment; $18-23$, mild cognitive impairment; and $\leq 17$, severe cognitive impairment [25].

\section{Stages of dementia}

The stages of dementia identified from the medical records were measured using the Korean version of the Expanded Clinical Dementia Rating (CDR) scale, which was translated into Korean by Choi et al. [26] based on the original CDR version by Hughes et al. [27] This scale consists of 6 domains: memory, orientation, judgement and problem-solving, community affairs, home and hobbies, and personal care. This scale is used to classify dementia into 5 stages. The score for the overall dementia stage is determined after comparing the base score for memory with the score for the other items. A score of 0 indicates non-demented; 0.5 , very mild dementia; 1 , mild dementia; 2, moderate dementia; 3, severe dementia [26].

\section{Depression}

The levels of depression identified from the respective medical records in this study were measured using the Short Form of Geriatric Depression Scale-Korea (SGDS-
$\mathrm{K})$, which was modified for the Korean elderly by Cho et al. [28] based on a 15-item excerpt from the 30-item Geriatric Depression Scale developed by Yesavage et al. [29] The SGDS-K is a binary scale consisting of closeended questions. A score of $\geq 8$ was interpreted as having depression.

\section{Activities of daily living}

The ADL identified through the respective medical records were measured using the Korean version of the Barthel ADL Index (K-BADL), originally reported by Wade and Collin [30] and translated into Korean by Kim et al. [31] The ADL Index consists of 10 items: bowels, bladder, glooming, toilet use, feeding, transfer, mobility, dressing, stairs, and bathing. The total score ranges from 0 to 20 points; a high score indicates an independent state, and a score of $\leq 14$ indicates a state in need of help from others [30].

\section{Instrumental activities of daily living}

The IADL identified from the respective medical records in this study was measured using the Seoul-IADL (SIADL), which was reconstructed by Koo et al. [32] based on the original IADL version reported by Lawton and Brody [33]. The IADL measures more complex functions than the ADL and consists of 15 items regarding the skills and actions required for maintaining a social life. The score for each item ranges from 0 to 3 points. The 
items included were actions such as using the telephone, shopping, preparing food/cooking, household chores, using the transportation, walking outdoors, taking medication, managing finances, grooming, using household appliances, managing belongings, unlocking and closing the entrance door, maintaining appointments, talking about recent events, and leisure/hobbies activities. A high score indicates higher levels of dependence; whereby a score of $<8$ is classified as being independent, and a score of $\geq 8$ is classified as needing help [32].

\section{Behavioural and psychological symptoms of dementia and family caregiver burden}

The BPSD and family caregiver burden identified through respective medical records in this study were measured using the Korean Neuropsychiatric Inventory (K-NPI), originally proposed by Cummings et al. [34] and Kaufer et al. [35], which was translated and modified into Korean by Choi et al. [36] K-NPI was included in CRCD caregiver questionnaires. The BPSD was scored by monitoring the caregivers' responses obtained from a self-reporting questionnaire wherein they selected the frequency (4-point scale) and severity (3-point scale) of the symptoms. The frequency and severity scores for each symptom were multiplied, and then the sum of the scores was used to measure the BPSD. A higher score for each symptom indicates a higher severity of the respective symptom, and a higher total score indicates a greater severity of overall BPSD. The caregiver burden for each BPSD item was rated from 0 to 5 points, and a higher total score indicates a higher caregiver burden.

\section{Statistical analysis}

The data were analysed using SPSS 22.0 and AMOS 22.0 programmes. The characteristics of the patients and their family caregivers were analysed using frequency, percentage, mean, and standard deviation. BPSD was classified using factor analysis. Factor extraction was performed using principal component analysis, followed by Varimax factor rotation. Before performing factor analysis, suitability of the data was tested using the Kaiser-Meyer-Olkin (KMO) and Bartlett's tests. The internal reliability of the classified BPSD symptoms was measured using Cronbach's $\alpha$. The correlation between the measured variables was determined using the Pearson's correlation coefficient.

The hypothetical model was tested using the structural equation model of analysis. The goodness-of-fit of the model was tested using $X^{2} / \mathrm{df}$, Goodness- of Fit Index (GFI), Adjusted Goodness-of Fit Index (AGFI), Comparative Fit Index (CFI), Normed Fit Index (NFI), Incremental Fit Index (IFI), Standardized Root Mean Square Residual (SRMR), and Root Mean Square Error of Approximation (RMSEA) [37]. The significance of the effects of the study model was tested using the bootstrap method.

\section{Results}

Characteristics of the patients and family caregivers

The mean total BPSD score was $17.68 \pm 20.67$, and the mean score for family caregiver burden was $9.65 \pm 11.12$. The characteristics of patients and family caregivers are shown in Table 1.

\section{Classification and type of BPSD symptom clusters}

The KMO measure is a value that verifies the correlation matrix to determine the goodness-of-fit for the sample size of all the variables. The KMO measure in this study was 0.83 , which was higher than the standard value of 0.50 , indicating an appropriate sample size. In addition, Bartlett's test of sphericity showed that statistical significance was less than 0.001 , thereby confirming the goodness-of-fit of the model.

Using a factor analysis based on the severity of 12 symptoms of BPSD, three factors were extracted. The variance for Factor 1, Factor 2, and Factor 3 was 2.85, 2.62, and 2.02, respectively. The explanatory power of Factor 1, Factor 2, and Factor 3 was 23.7, 21.8, and $16.8 \%$, respectively. The total explanatory power of the three factors was $62.3 \%$ of the total variance.

Symptom cluster 1 (Factor 1) described hyperactivity symptoms, which included disinhibition, irritability, and agitation/aggression. Symptom cluster 2 (Factor 2) described psychosis symptoms, which included hallucinations, anxiety, elation/euphoria, delusions, and depression/ dysphoria. Symptom cluster 3 (Factor 3) described physical behaviour symptoms, which included appetite and eating abnormalities, apathy/indifference, aberrant motor behaviour, sleep, and night-time behaviour disturbances. Cronbach's $\alpha$ was 0.85 for hyperactivity symptoms, 0.77 for psychosis symptoms, and 0.68 for physical behaviour symptoms (Table 2).

\section{Correlation between clinical characteristics and BPSD in patients and family caregiver burden}

Family caregiver burden is positively correlated with the stages of dementia, IADL, hyperactivity symptoms, psychosis symptoms, and physical behaviour symptoms and negatively correlated with cognitive function and ADL (Table 3).

\section{Testing the hypothetical and modified models}

While the results of testing the goodness-of-fit of the hypothetical model (Fig. 2) showed that GFI $=0.99$, CFI $=$ 0.99 , IFI $=0.99$, and SRMR $=0.36$ met the goodness-of-fit criteria, the results showed that $\chi^{2} / \mathrm{df}=6.56$, AGFI $=0.62$, and RMSEA $=0.18$, which indicated poor fit. To improve reliability, the model was modified, removing insignificant 
Table 1 Characteristics of the family patients and family caregivers $(N=170)$

\begin{tabular}{|c|c|c|c|c|}
\hline \multicolumn{4}{|l|}{ Characteristics } & \multirow{2}{*}{$\begin{array}{l}\mathbf{n}(\%) \text { or Mean } \pm \text { SD } \\
57(33.5)\end{array}$} \\
\hline Patients & General & Sex & Male & \\
\hline & & & Female & $113(66.5)$ \\
\hline & & Age (years) & $50-74$ & $66(38.8)$ \\
\hline & & & $\geq 75$ & $104(61.2)$ \\
\hline & & & & $76.5 \pm 8.0$ \\
\hline & & Level of education & Never educated & $62(36.5)$ \\
\hline & & & Primary-junior high school & $60(35.3)$ \\
\hline & & & High school or above & $48(28.2)$ \\
\hline & & Smoking & Yes & $66(38.8)$ \\
\hline & & & No & $104(61.2)$ \\
\hline & & Drinking & Yes & $60(35.3)$ \\
\hline & & & No & $110(64.7)$ \\
\hline & Clinical & Cognitive function & $\geq 24$ (no cognitive impairment) & $98(57.6)$ \\
\hline & & & 18-23 (mild cognitive impairment) & $54(31.8)$ \\
\hline & & & $\leq 17$ (severe cognitive impairment) & $18(10.6)$ \\
\hline & & Stages of dementia & 0.5 (very mild) & $53(31.2)$ \\
\hline & & & 1 (mild) & $102(60.0)$ \\
\hline & & & 2 (moderate) & $15(8.8)$ \\
\hline & & Depression & $<8$ (no depressive symptom) & $109(64.1)$ \\
\hline & & & $\geq 8$ (having depressive symptoms) & $61(35.9)$ \\
\hline & & Activities of daily living & $\leq 14$ (help needed) & $21(12.4)$ \\
\hline & & & $>14$ (help not needed) & $149(87.6)$ \\
\hline & & Instrumental activities of daily living & $<8$ (help not needed) & $30(17.6)$ \\
\hline & & & $\geq 8$ (help needed) & $140(82.4)$ \\
\hline & & BPSD & & $17.68 \pm 20.67$ \\
\hline \multirow[t]{13}{*}{ Family caregivers } & General & Sex & Male & $65(38.2)$ \\
\hline & & & Female & $105(61.8)$ \\
\hline & & Age (years) & $20-49$ & $58(34.1)$ \\
\hline & & & $50-64$ & $69(40.6)$ \\
\hline & & & $65-74$ & $26(15.3)$ \\
\hline & & & $\geq 75$ & $17(10.0)$ \\
\hline & & & & $55.4 \pm 13.4$ \\
\hline & & Relationship with the patient & Spouse & $48(28.2)$ \\
\hline & & & Son/daughter & $98(57.6)$ \\
\hline & & & Other & $24(14.1)$ \\
\hline & & Living with the patient & Yes & $108(63.5)$ \\
\hline & & & No & $62(36.5)$ \\
\hline & & Burden & & $9.65 \pm 11.12$ \\
\hline
\end{tabular}

BPSD Behavioural Psychological Symptoms of Dementia

paths based on the significance level of 0.05 while simultaneously verifying the model fit and modification indices (Fig. 3). Successively, the goodness-of-fit indices of the modified model were $\chi^{2} / \mathrm{df}=1.46, \mathrm{GFI}=0.99, \mathrm{AGFI}=$ 0.93, CFI $=0.99, \mathrm{NFI}=.099, \mathrm{IFI}=0.99, \mathrm{SRMR}=0.03$, and RMSEA $=0.05$, which indicated a good fit.
The model indicated that nine paths were significant (Table 4, Fig. 3). The results of analysing the direct, indirect, and total effects of the modified model (Table 4) showed that ADL $(\gamma=-0.186, p=0.016)$ and IADL $(\gamma=$ $0.273, p<0.001)$ had significant direct and total effects on hyperactivity symptoms; stages of dementia $(\gamma=0.22$, 
Table 2 Factor analysis and classification of BPSD symptom clusters $(N=170)$

\begin{tabular}{|c|c|c|c|c|}
\hline Cluster & Symptom & Factor 1 & Factor 2 & Factor 3 \\
\hline \multirow{3}{*}{$\begin{array}{l}\text { Symptom cluster } 1 \\
\text { Hyperactivity symptoms }\end{array}$} & Disinhibition & 0.87 & & \\
\hline & Irritability & 0.84 & & \\
\hline & Agitation/aggression & 0.75 & & \\
\hline \multirow{5}{*}{$\begin{array}{l}\text { Symptom cluster } 2 \\
\text { Psychosis symptoms }\end{array}$} & Hallucinations & & 0.71 & \\
\hline & Anxiety & & 0.70 & \\
\hline & Elation/euphoria & & 0.70 & \\
\hline & Delusions & & 0.64 & \\
\hline & Depression/dysphoria & & 0.54 & \\
\hline \multirow{4}{*}{$\begin{array}{l}\text { Symptom cluster } 3 \\
\text { Physical behaviour symptoms }\end{array}$} & Appetite and eating abnormalities & & & 0.84 \\
\hline & Apathy/indifference & & & 0.65 \\
\hline & Aberrant motor behaviour & & & 0.59 \\
\hline & Sleep and night-time behaviour disturbances & & & 0.44 \\
\hline Cronbach's a & & 0.85 & 0.77 & 0.68 \\
\hline Eigen values & & 2.85 & 2.62 & 2.02 \\
\hline Explained variance (\%) & & 23.7 & 21.8 & 16.8 \\
\hline Cumulative variance (\%) & & 23.7 & 45.5 & 62.3 \\
\hline
\end{tabular}

$p=0.003)$ and IADL $(\gamma=0.28, p<0.001)$ had significant direct and total effects on psychosis symptoms, while the stages of dementia $(\gamma=0.27, p<0.001)$ and ADL $(\gamma=-$ $0.27, p<0.001)$ had significant direct and total effects on physical behavioural symptoms.

Factors affecting family caregiver burden showed direct and total effects in the order of psychosis $(\gamma=0.47$, $p<0.001)$, hyperactivity $(\gamma=0.30, p<0.001)$, and physical behaviour $(\gamma=0.28, p<0.001)$. Stages of dementia, ADL, and IADL had significant indirect and total effects, and stages of dementia $(\gamma=0.18, p=0.002)$ and IADL $(\gamma=0.21, p<0.001)$ had significant positive indirect and total effects. However, ADL $(\gamma=-0.13, p=0.005)$ had significant negative indirect and total effects. Therefore, stages of dementia, ADL, and IADL had indirect effects on family caregiver burden through hyperactivity, psychosis, and physical behaviour symptoms, indicating that BPSD had a complete mediating effect.

\section{Discussion}

Since BPSD is the most difficult problem to deal with for family caregivers, who are the primary caregiver for the elderly with dementia, figuring out how BPSD affects the family caregivers' burden is critical in that it can provide not only the well-being of the family caregivers but also further basic data that can contribute to improving the quality of life (QOL) of AD patients. Our study focuses on classifying BPSD as a symptom cluster and, subsequently, linking these factors that affect BPSD to each cluster, which differentiates this study from previous studies.

Mean scores for BPSD were higher than those for family caregiver burden in patients with AD. These scores of our study were higher than those reported in a study [38] of patients with AD living in veterans' homes in Taiwan using the same tool. However, these scores were

Table 3 Correlation between clinical characteristics and BPSD in patients and family caregiver burden $(N=170)$

\begin{tabular}{|c|c|c|c|c|c|c|c|c|c|}
\hline & 1 & 2 & 3 & 4 & 5 & 6 & 7 & 8 & 9 \\
\hline 1. Cognitive function & 1 & & & & & & & & \\
\hline 2. Stages of dementia & $-0.62^{*}$ & 1 & & & & & & & \\
\hline 3. Depression & -0.12 & 0.05 & 1 & & & & & & \\
\hline 4. Activities of daily living & $0.22^{*}$ & $-0.35^{*}$ & -0.07 & 1 & & & & & \\
\hline 5. Instrumental activities of daily living & $-0.35^{*}$ & $0.59^{*}$ & -0.04 & $-0.65^{*}$ & 1 & & & & \\
\hline 6. Hyperactivity symptoms & $-0.24^{*}$ & $0.32^{*}$ & $-0.16^{*}$ & $-0.36^{*}$ & $0.43^{*}$ & 1 & & & \\
\hline 7. Psychosis symptoms & $-0.32^{*}$ & $0.43^{*}$ & 0.01 & $-0.25^{*}$ & $0.44^{*}$ & $0.62^{*}$ & 1 & & \\
\hline 8. Physical behaviour symptoms & $-0.29^{*}$ & $0.40^{*}$ & 0.01 & $-0.35^{*}$ & $0.41^{*}$ & $0.57^{*}$ & $0.57^{*}$ & 1 & \\
\hline 9. Family caregiver's burden & $-0.29^{*}$ & $0.39^{*}$ & -0.02 & $-0.35^{*}$ & $0.49^{*}$ & $0.74^{*}$ & $0.81^{*}$ & $0.71^{*}$ & 1 \\
\hline
\end{tabular}




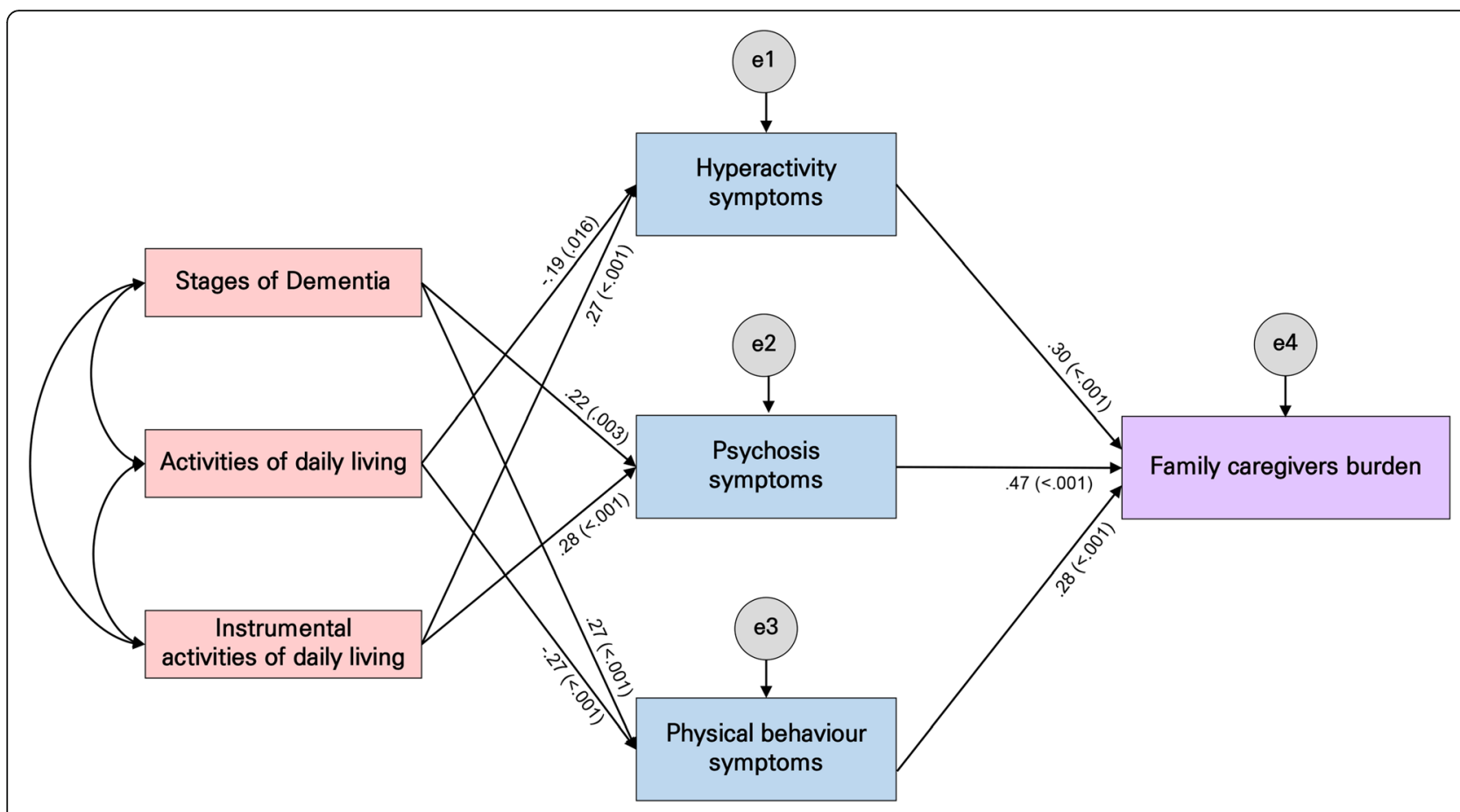

Fig. 3 Path diagram of the modified model

lower than those reported in a study of outpatients with dementia in Portugal [39]. The reason that the scores for BPSD and caregiver burden were lower in the study by Hsu et al. [38] than in our study could be because the subjects of the former were living in veterans' homes and their caregivers were nurses, whereas the patients of this study were diagnosed with $\mathrm{AD}$ at the outpatient clinic at a tertiary general hospital and their caregivers were family members. It is also thought that the subjects of the study conducted by Melo et al. [39] had various types of dementia, including $\mathrm{AD}$, frontotemporal dementia, and vascular dementia. The findings of this study indicate that a higher BPSD is associated with a higher family caregiver burden. However, because there is a difference in the subjects, their residence, and the characteristics of caregivers between this study and previous studies, it is thought that there may be a variable difference in the levels of BPSD and caregiver burden.

Table 4 Direct, indirect, and total effects of the modified model $(N=170)$

\begin{tabular}{|c|c|c|c|c|c|c|c|c|c|c|}
\hline \multirow{3}{*}{$\begin{array}{l}\text { Endogenous variables } \\
\text { Hyperactivity symptoms }\end{array}$} & \multirow{3}{*}{$\begin{array}{l}\text { Exogenous variables } \\
\text { Activities of daily living }\end{array}$} & \multirow{3}{*}{$\begin{array}{l}\text { C.R. } \\
-2.41\end{array}$} & \multirow{3}{*}{$\begin{array}{l}(p) \\
(0.016)\end{array}$} & \multirow{3}{*}{$\begin{array}{l}\text { SMC } \\
0.18\end{array}$} & \multirow{2}{*}{\multicolumn{2}{|c|}{$\begin{array}{l}\text { Direct effect } \\
\text { SE }(p)\end{array}$}} & \multirow{2}{*}{\multicolumn{2}{|c|}{$\frac{\text { Indirect effect }}{\text { SE }(p)}$}} & \multirow{2}{*}{\multicolumn{2}{|c|}{$\begin{array}{l}\text { Total effect } \\
\text { SE }(p)\end{array}$}} \\
\hline & & & & & & & & & & \\
\hline & & & & & -0.19 & $(0.016)$ & & & -0.19 & $(0.016)$ \\
\hline & Instrumental activities of daily living & 3.34 & $(<.001)$ & & 0.27 & $(<.001)$ & & & 0.27 & $(<.001)$ \\
\hline Psychosis symptoms & Stages of Dementia & 3.02 & $(0.003)$ & 0.20 & 0.22 & $(0.003)$ & & & 0.22 & $(0.003)$ \\
\hline & Instrumental activities of daily living & 3.71 & $(<.001)$ & & 0.28 & $(<.001)$ & & & 0.28 & $(<.001)$ \\
\hline Physical behaviour symptoms & Stages of Dementia & 4.00 & $(<.001)$ & 0.19 & 0.27 & $(<.001)$ & & & 0.27 & $(<.001)$ \\
\hline & Activities of daily living & -3.96 & $(<.001)$ & & -0.27 & $(<.001)$ & & & -0.27 & $(<.001)$ \\
\hline Family caregiver's burden & Hyperactivity symptom & 6.19 & $(<.001)$ & 0.78 & 0.30 & $(<.001)$ & & & 0.30 & $(<.001)$ \\
\hline & Psychosis symptom & 9.69 & $(<.001)$ & & 0.47 & $(<.001)$ & & & 0.47 & $(<.001)$ \\
\hline & Physical behaviour symptom & 5.96 & $(<.001)$ & & 0.28 & $(<.001)$ & & & 0.28 & $(<.001)$ \\
\hline & Stages of Dementia & & & & & & 0.18 & $(0.002)$ & 0.18 & $(0.002)$ \\
\hline & Activities of daily living & & & & & & -0.13 & $(0.005)$ & -0.13 & $(0.005)$ \\
\hline & Instrumental activities of daily living & & & & & & 0.21 & $(0.005)$ & 0.21 & $(0.005)$ \\
\hline
\end{tabular}


Nevertheless, $71.8 \%$ of the subjects were under-educated people, and it is necessary to check the impact of this education level. In the study of García-Alberca et al. [40], years of education, one of the $\mathrm{AD}$ patient general characteristics showed correlation with a range of depression in the tests of measurements taken to determine caregivers' burden. However, another research [41], which showed no correlation between years of education and caregiver burden, the other [42] showed a faster cognitive decline in $\mathrm{AD}$ patients with higher education levels. Further studies with repetition of the analyses will be needed to determine whether or not patient's cognition and caregiver burden are related to the patient's education level.

The results of the factor analysis of 12 symptoms of BPSD showed that BPSD can be classified into three symptom clusters: hyperactivity, psychosis, and physical behaviour symptom clusters. Hyperactivity symptoms consisted of disinhibition, irritability, and agitation/aggression, which were consistent with the cluster name and pattern reported in a study conducted by Kang et al. [18] In addition, studies with the same cluster name and pattern [15] and studies with similar cluster patterns but different cluster names [17] were also identified. Psychosis symptoms consisted of hallucinations, anxiety, elation/euphoria, delusions, and depression/dysphoria. Except for depression/dysphoria, the remaining symptoms were found to be symptoms included in the psychosis symptom cluster identified in previous studies [15-18, 43]. However, in these studies, depression was also classified as $\operatorname{mood}[17$, 43], emotional [16], and affective clusters [15, 18]. Moreover, in other studies, euphoria has not been grouped together with other symptoms but has been classified as a single symptom cluster $[15,17]$. Physical behaviour symptoms consisted of appetite and eating abnormalities, apathy/indifference, aberrant motor behaviour, and sleep and night-time behaviour disturbances. A few previous studies [17, 18, 43] reported similar cluster patterns with different cluster names than those of this study, while other studies have reported that aberrant motor behaviour was classified as a common symptom belonging to a symptom cluster of the same name "physical behaviour symptoms." [16, 17] The diversity and variation in cluster classifications and nomenclature, with varying agreements, similarities, and differences between studies, are thought to be due to differences in the characteristics of the subjects, sample size, and analytical methods. While this study found correlations between each related symptom, further studies are required to confirm its BPSDsymptom-cluster classification, determine generalised BPSD clusters, and propose intervention programmes through cluster-specific approaches.

Testing the model of this study showed that the three symptom clusters had a direct effect on the family caregiver burden, whereby the psychosis symptoms cluster was the most influential. The results also found that the stages of dementia, ADL, and IADL indirectly affected family caregiver burden through hyperactivity, psychosis, and physical behaviour symptoms, indicating that BPSD had a total mediating effect. Garre-Olmo et al. [44] reported that BPSD in patients with AD had a direct effect on caregiver burden and ADL had an indirect effect on caregiver burden through BPSD, which was consistent with the results of this study. In addition, a study by Onishi et al. [45] showed that the severity of dementia and physical disability had a direct effect on caregiver burden, which was similar to the results of this study. In the modified model of this study, cognitive function demonstrated no effect on BPSD and caregiver burden. In the study conducted by Kang et al. [41], cognitive impairment status, sub-domains of neuropsychological test's memory function, and frontal executive function showed correlation with caregiver burden measured using K-MMSE. The results are similar to those that did not act as an influence factor in the regression analysis. However, in the meta-analysis for family caregivers of home-dwelling elderly people with dementia [46], the factors such as family caregiver's characteristics, problematic behaviour, cognition (memory), stages of dementia, and ADL have an effect on the caregiver burden. In particular, ADL [47, 48] and IADL [48] are also factors that affect the QOL for dementia patients. Therefore, when providing interventions for caregiver burden due to BPSD in patients with AD, it is necessary to explore strategies and algorithms that consider the different stages of dementia to be able to develop the necessary interventions, while focusing on slowing disease progression and improving functional independence in daily living. Furthermore, repeated studies are needed to determine whether cognition acts as an influencing factor on caregivers' burden by utilising various scales that are used to measure cognition.

In accordance with the "Global action plan on the public health response to dementia (2017-2025)" announced by the World Health Organization [49], the Dementia Friendly Communities emerged, supported by the government's Dementia Management policy. The Korean Ministry of Health and Welfare has proposed a dementia system, and they plan to institute dementia care centres in villages as a national imperative, which is part of its continual expansion strategy [50]. However, this is a long-term and complex project that requires appropriate preparation, budget allocations, and consensus among community members. It is, therefore, recommended that the government authorities fully support the development and establishment of systematic strategies to expand programmes and actively publicise them, so that patients with dementia and their family caregivers can utilise them. 
Since patients with dementia are in chronic and disabling conditions and the family caregivers can be seen as a hidden patient [51], strategies to reduce caregivers' burden due to BPSD and improve caregivers' QOL should also be considered. In a previous study [52], if the caregiver burden was high, the occurrence of $\mathrm{AD}$ in patients with neuropsychiatric symptoms (NPS) was more frequent and severe. Engagement coping strategies of the caregiver showed a mediating effect between caregiver burden and NPS. Another study [53] that measured coping strategies of the $\mathrm{AD}$ patient's caregiver utilised the Coping Inventory for Stressful Situations (CISS). This study reported that the success of the caregiver is related to task-focused and avoidance-focused strategies. The results of the other study showed that emotion-focused coping strategies decreased BPSD and caregiver burnout [54]. Heavy burden and stress among caregivers who take care of dementia patients can lead to poor QOL of AD patients [55]. A correlation was observed between caregiver burden and QOL [56] because BPSD and caregivers' burden have an effect on the QOL of the caregiver [48, 57]; adequate coping strategies for reducing the burden and stress are required for improving the QOL of the caregiver [58]. In particular, Korean dementia families tend to use passive attitudes, avoidance, and anger [59]; therefore, they need an active intervention to train their families' effective problemoriented coping.

Although there is a need for customised intervention according to the preference of patients and their family caregiver, in Korea, it is difficult to apply a personcentred care model that individually supports the target, as it is based on specialised medical models such as doctors and social workers. In addition, the institutional foundation for universal welfare based on the social model is not yet firmly established, as the cost of health and social services is eased, but it remains an economic burden to dementia patients and their family members. Therefore, it is necessary to decide the direction of dementia policy through philosophical discussion in Korea, deviating from simply comparing and applying dementia policy cases in other countries [60]. Discussion on person-centred dementia care has recently expanded $[61,62]$ to ensure that dementia patients and their family caregivers are the main agents of the policy.

The findings of this study may not be applicable to the general population as the participants in this study were outpatients. Thus, these findings are limited in terms of generalisation and interpretation. In addition, this study used data previously collected for diagnostic and therapeutic purposes and was limited in describing family caregivers' burden using a multidimensional approach that included characteristics, such as social position, monthly income, work position, caregiving time demands, home care service costs, medical device costs, educational level, and psychological factors [63-65]. Longitudinal studies covering the time span of disease progression, commencing from the time of the diagnosis of dementia, are recommended to determine changes in the factors affecting the classification of BPSD and family caregivers' burden as the disease progresses. Finally, it is necessary to analyse how the coping strategies of the caregiver medicate the BPSD symptom clusters, the caregiver burden, and the QOL of the patient and family caregiver while controlling the general characteristics of the patient and the caregiver, such as sex, age, and education level.

\section{Conclusions}

This study confirmed that the stages of dementia, ADL, and IADL affected BPSD and that BPSD, in turn, affected family caregivers' burden; therefore, this study provides a basis for broadening the understanding of family caregivers' burden. The results of this study are important, as they provide a strong foundation for future studies on multidimensional approaches to determine the relationship between BPSD in patients with AD and their family caregivers' burden. These results can also be used for the development of treatment and nursing strategies for $\mathrm{AD}$ patients in clinical settings and can further contribute to policy development.

\section{Abbreviations \\ AD: Alzheimer's disease; BPSD: Behavioural and psychological symptoms of dementia; ADL: Activities of daily living; IADL: Instrumental activities of daily living; EMR: Electronic medical records; CRCD: Clinical Research Center for Dementia; K-MMSE: Korean version of the Mini-Mental State Examination; CDR: Clinical Dementia Rating; SGDS-K: Short form of Geriatric Depression Scale-Korea; K-BADL: Korean version of the Barthel ADL Index; S-IADL: Seoul- instrumental activities of daily living; K-NPI: Korean Neuropsychiatric Inventory; KMO: Kaiser-Meyer-Olkin; GFI: Goodness-of-Fit Index; AGFI: Adjusted Goodness-of-Fit Index; CFI: Comparative Fit Index; NFI: Normed Fit Index; IFI: Incremental Fit Index; SRMR: Standardized Root Mean Square Residual; RMSEA: Root Mean Square Error of Approximation}

\section{Acknowledgements \\ We would like to thank Editage (www.editage.co.kr) for English language editing.}

\section{Authors' contributions \\ BK contributed towards the investigation, data curation, methodology, analysis using software, and writing-reviewing and editing. GON contributed towards the investigation, validation, and writing-original draft and editing. KK contributed towards supervision and conceptualisation. All authors read and approved the final manuscript.}

\section{Funding}

Not applicable.

\section{Availability of data and materials}

The datasets generated and analysed during the current study are not publicly available due [personally sensitive medical records] but are available from the corresponding author on reasonable request. 


\section{Declarations}

\section{Ethics approval and consent to participate}

The study was approved by the Institutional Review Board (IRB) Department of Chung-Ang University Hospital (approval No.: C20160791822) for ethical protection of the participants and for accessing their medical records, including the electronic medical records of the respective patients. The institutional review board waived the requirement of written informed consents from patients and their caregivers since the data were historical and had already been collected for diagnostic and therapeutic purposes. The institution also determined that this study was eligible for an exempt status based on the exempt application stating that private data, such as those of patient hospital number, and family caregivers' contacts, will not be recorded.

\section{Consent for publication}

Not applicable.

\section{Competing interests}

The authors declare that they have no competing interests.

\section{Author details}

'Department of Nursing, Catholic Kwandong University, Gangneung, South Korea. ${ }^{2}$ Department of Nursing, Konyang University, 158 Gwanjeodong-ro, Seo-gu, Daejeon 35365, South Korea. ${ }^{3}$ Department of Nursing, Chung-Ang University, Seoul, South Korea.

\section{Received: 29 October 2020 Accepted: 18 February 2021} Published online: 05 March 2021

\section{References}

1. National Institute of Dementia. Korean dementia observatory 2019. https://a nsim.nid.or.kr/community/pds_view.aspx?bid=209. Accessed 13 September 2020.

2. WHO. Dementia 2019. https://www.who.int/news-room/fact-sheets/detail/ dementia. Accessed 28 August 2020.

3. Cerejeira J, Lagarto L, Mukaetova-Ladinska EB. Behavioural and psychological symptoms of dementia. Front Neurol. 2012;3:73.

4. Mintzer JE, Hoernig KS, Mirski DF. Treatment of agitation in patients with dementia. Clin Geriatr Med. 1998;14:147-75.

5. Song JA, Park JW, Kim HJ. Impact of behavioral and psychological symptoms of dementia on caregiver burden in nursing homes. J Korean Gerontololgical Nurs. 2013;15:62-74

6. Brodaty $H$, Donkin M. Family caregivers of people with dementia. Dialogues Clin Neurosci. 2009:11:217-28.

7. Kwon OD, Kim TW, Park MY, Yi SD, Yi HA, Lee HW, et al. Factors affecting caregiver burden in family caregivers of patients with dementia. Dem Neurocognitive Disord. 2013;12:107-13.

8. Kim H, Chang M, Rose K, Kim S. Predictors of caregiver burden in caregivers of individuals with dementia. J Adv Nurs. 2012;68:846-55.

9. Yoo IY, Kim MH. Influencing factors on care burden in the caregivers of demented elderly. J Korean Gerontol Nurs. 2006;8:47-57.

10. Huang SS, Lee MC, Liao YC, Wang WF, Lai TJ. Caregiver burden associated with behavioral and psychological symptoms of dementia (BPSD) in Taiwanese elderly. Arch Gerontol Geriatr. 2012;55:55-9.

11. Kim KS, Choi ES, Park SA. A study on behavioral and psychological symptoms of dementia (BPSD) among dementia elderly in an institutional setting. J Korean Gerontol Soc. 2007;27:137-52.

12. Gim MS, Choi YM, Lee DW. Relationship between premorbid personality and behavioral and psychological symptoms in dementia in Korean patients with Alzheimer's disease. J Korean Geriatr Psythiatry. 2014;18:81-5.

13. Okura T, Plassman BL, Steffens DC, Llewellyn DJ, Potter GG, Langa KM. Prevalence of neuropsychiatric symptoms and their association with functional limitations in older adults in the United States: the aging, demographics, and memory study. J Am Geriatr Soc. 2010;58:330-7.

14. Cummings JL. McRae T, Zhang R, the donepezil-sertraline study group. Effects of donepezil on neuropsychiatric symptoms in patients with dementia and severe behavioral disorders. Am J Geriatr Psychiatry. 2006;14: 605-12.

15. van der Linde RM, Dening T, Matthews FE, Brayne C. Grouping of behavioural and psychological symptoms of dementia. Int J Geriatr Psychiatry. 2014;29:562-8.
16. Garre-Olmo J, López-Pousa S, Vilalta-Franch J, de Gracia BM, Vilarrasa AB. Grouping and trajectories of the neuropsychiatric symptoms in patients with Alzheimer's disease, part l: symptom clusters. J Alzheimers Dis. 2010;22: 1157-67.

17. Cheng ST, Kwok T, Lam LC. Neuropsychiatric symptom clusters of Alzheimer's disease in Hong Kong Chinese: prevalence and confirmatory factor analysis of the neuropsychiatric inventory. Int Psychogeriatr. 2012;24: 1465-73.

18. Kang HS, Ahn IS, Kim JH, Kim DK. Neuropsychiatric symptoms in Korean patients with Alzheimer's disease: exploratory factor analysis and confirmatory factor analysis of the neuropsychiatric inventory. Dement Geriatr Cogn Disord. 2010;29:82-7.

19. McKhann G, Drachman D, Folstein M, Katzman R, Price D, Stadlan EM. Clinical diagnosis of Alzheimer's disease: report of the NINCDS-ADRDA work group under the auspices of Department of Health and Human Services Task Force on Alzheimer's disease. Neurology. 1984;34:939-44.

20. American Psychiatric Association. Diagnostic and Statistical Manual of Mental Disorders. 4th ed. Washington DC: American Psychiatric Association; 1994.

21. Mundfrom DJ, Shaw DG, Ke TL. Minimum sample size recommendations for conducting factor analyses. Int J Test. 2005;5:159-68.

22. Cho SB. LISREL structural equation model. Seoul: Youngjimunhwasa; 1999.

23. Kang Y, Na DL, Hahn S. A validity study on the Korean mini-mental state examination (K-MMSE) in dementia patients. J Korean Neurol ASSN. 1997;15: 300-8.

24. Folstein MF, Folstein SE, McHugh PR. 'Mini-mental state'. A practical method for grading the cognitive state of patients for the clinician. J Psychiatr Res. 1975;12:189-98.

25. Folstein MF, Folstein SE, Fanjiang G. Mini-Mental State Examination: clinical Guide. Psychol Assess Resour. 2002.

26. Choi SH, Na DL, Lee BH, Hahm D-S, Jeong JH, Yoon SJ, et al. Estimating the validity of the Korean version of expanded clinical dementia rating (CDR) scale. J Korean Neurol Assoc. 2001;19:585-91.

27. Hughes CP, Berg L, Danziger WL, Coben LA, Martin RL. A new clinical scale for the staging of dementia. Br J Psychiatry. 1982;140:566-72.

28. Cho MJ, Bae JN, Suh GH, Hahm BJ, Kim JK, Lee DW. Validation of geriatric depression scale, Korean version (GDS) in the assessment of DSM-III-R major depression. J Korean Neuropsychiatr Assoc. 1999;38:48-63.

29. Yesavage JA, Brink TL, Rose $T L$, Lum $O$, Huang $V$, Adey $M$, et al. Development and validation of a geriatric depression screening scale: a preliminary report. J Psychiatr Res. 1982;17:37-49.

30. Collin C, Wade DT, Davies S, Horne V. The Barthel ADL index: a reliability study. Int Disabil Stud. 1988;10:61-3.

31. Kim SY, Won CW, Rho YG. The validity and reliability of Korean version of Bathel ADL index. Korean J Fam Med. 2004;25:534-41.

32. Koo HM, Kim JH, Kwon EJ. A study of the reliability of validity of Seoulinstrumental activities of daily living (S-IADL). Psychiatry Investig. 2004;43: 189-99.

33. Lawton MP, Brody EM. Assessment of older people: self-maintaining and instrumental activities of daily living. Gerontologist. 1969:9:179-86.

34. Cummings JL, Mega M, Gray K, Rosenberg-Thompson S, Carusi DA, Gornbein J. The neuropsychiatric inventory: comprehensive assessment of psychopathology in dementia. Neurology. 1994;44:2308-14.

35. Kaufer Dl, Cummings JL, Christine D, Bray T, Castellon S, Masterman D, et al. Assessing the impact of neuropsychiatric symptoms in Alzheimer's disease: the neuropsychiatric inventory caregiver distress scale. J Am Geriatr Soc. 1998;46:210-5.

36. Choi SH, Na DL, Kwon HM, Yoon SJ, Jeong JH, Ha CK. The Korean version of the neuropsychiatric inventory: a scoring tool for neuropsychiatric disturbance in dementia patients. J Korean Med Sci. 2000;15:609-15.

37. Yu JP. The concept and understanding of professor Yu Jong-pil's structural equation model. Seoul: Hannarae; 2012

38. Hsu TJ, Tsai HT, Hwang AC, Chen LY, Chen LK. Predictors of nonpharmacological intervention effect on cognitive function and behavioral and psychological symptoms of older people with dementia. Geriatr Gerontol Int. 2017;17(Supplement 1):28-35.

39. Melo G, Maroco J, Lima-Basto M, de Mendonca A. Personality of the caregiver influences the use of strategies to deal with the behavior of persons with dementia. Geriatr Nurs. 2017;38:63-9.

40. Garcia-Alberca JM, Lara JP, Berthier ML. Anxiety and depression in caregivers are associated with patient and caregiver characteristics in Alzheimer's disease. Int J Psychiatry Med. 2011;41:57-69. 
41. Kang HS, Myung W, Na DL, Kim SY, Lee JH, Han SH, et al. Factors associated with caregiver burden in patients with Alzheimer's disease. Psychiatry Investig. 2014;11:152-9.

42. Scarmeas N, Albert SM, Manly JJ, Stern Y. Education and rates of cognitive decline in incident Alzheimer's disease. J Neurol Neurosurg Psychiatry. 2006; 77:308-16.

43. Petrovic M, Hurt C, Collins D, Burns A, Camus V, Liperoti R, et al. Clustering of behavioural and psychological symptoms in dementia (BPSD): a European Alzheimer's disease consortium (EADC) study. Acta Clin Belg. 2007:62:426-32.

44. Garre-Olmo J, Vilalta-Franch J, Calvó-Perxas L, Turró-Garriga O. A path analysis of patient dependence and caregiver burden in Alzheimer's disease. Int Psychogeriatr IPA. 2016;28:1133-41.

45. Onishi J, Suzuki Y, Umegaki H, Nakamura A, Endo H, Iguchi A. Influence of behavioral and psychological symptoms of dementia (BPSD) and environment of care on caregivers' burden. Arch Gerontol Geriatr. 2005;41: 159-68.

46. Kim EK, Park H. Factors associated with burden of family caregivers of home-dwelling elderly people with dementia: a systematic review and meta-analysis. Korean J Adult Nurs. 2019;31:351-64.

47. Kim H, Lee YW, Choi SH, Ham YS. Factors influencing quality of life of elderly people with dementia. J Korean Academy of Fundamentals of Nurs. 2018;25:79-88

48. Akpınar Söylemez B, Küçükgüçlü Ö, Akyol MA, Isik AT. Quality of life and factors affecting it in patients with Alzheimer's disease: a cross-sectional study. Health Qual Life Outcomes. 2020;18:304.

49. $\mathrm{WHO}$. The global action plan on the public health response to dementia 2017-2025. https://www.who.int/mental_health/neurology/dementia/a ction_plan_2017_2025/en 2017. Accessed 13 September 2020.

50. Ministry of Health and Welfare, National Institute of Dementia. Global trends of dementia policy 2019. https://www.nid.or.kr/info/dataroom_view.a spx?bid=205 2020. Accessed 13 September, 2020.

51. Roche V. The hidden patient: addressing the caregiver. Am J Med Sci. 2009; 337:199-204.

52. Garcia-Alberca JM, Lara JP, Garrido V, Gris E, Gonzalez-Herero V, Lara A. Neuropsychiatric symptoms in patients with Alzheimer's disease: the role of caregiver burden and coping strategies. Am J Alzheimers Dis Other Dementias. 2014;29:354-61.

53. lavarone A, Ziello AR, Pastore F, Fasanaro AM, Poderico C. Caregiver burden and coping strategies in caregivers of patients with Alzheimer's disease. Neuropsychiatr Dis Treat. 2014;10:1407-13.

54. Li R, Cooper C, Barber J, Rapaport P, Griffin M, Livingston G. Coping strategies as mediators of the effect of the START (strategies for RelaTives) intervention on psychological morbidity for family carers of people with dementia in a randomised controlled trial. J Affect Disord. 2014;168:298-305.

55. Brody H, Donkin M. Family caregivers of people with dementia. Dialogues Clin Neurosci. 2009;19:211-7.

56. Tulek Z, Baykal D, Erturk S, Bilgic B, Hanagasi H, Gurvit IH. Caregiver burden, quality of life and related factors in family caregivers of dementia patients in Turkey. Issues Ment Health Nurs. 2020;41:741-9.

57. Liao X, Huang Y, Zhang Z, Zhong S, Xie G, Wang L, Xiao H. Factors associated with health-related quality of life among family caregivers of people with Alzheimer's disease. Psychogeriatrics. 2020;20:398-405.

58. Monteiro AMF, Santos RL, Kimura N, Baptista MAT, Dourado MCN. Coping strategies among caregivers of people with Alzheimer disease: a systematic review. Trends Psychiatry Psychother. 2018;40:258-68.

59. Kim CM. The types of coping strategies in family caregivers of demented elderly. J Korean Community Nurs. 2003;14:351-61.

60. Lee HS. An analysis of the UK's dementia response policy and its implications: focusing on Scotland's national dementia strategy. Health Social Welfare Rev. 2019;39:72-107.

61. Dementia Initiative. Dementia care: The quality chasm. http://www.ccal.org/ national-dementia-initiative/white-paper. Accessed 8 February, 2021

62. Brooker D. Person-Centred dementia care - making services better. London: Jessica Kingsley Publishers Ltd; 2006.

63. Maresova P, Lee S, Fadeyi OO, Kuca K. The social and economic burden on family caregivers for older adults in the Czech Republic. BMC Geriatr. 2020; 20:171.
64. Van der Lee J, Bakker TJ, Duivenvoorden HJ, Dröes RM. Multivariate models of subjective caregiver burden in dementia: a systematic review. Ageing Res Rev. 2014;15:76-93.

65. Chiao CY, Wu HS, Hsiao CY. Caregiver burden for informal caregivers of patients with dementia: a systematic review. Int Nurs Rev. 2015;62:340-50.

\section{Publisher's Note}

Springer Nature remains neutral with regard to jurisdictional claims in published maps and institutional affiliations.
Ready to submit your research? Choose BMC and benefit from:

- fast, convenient online submission

- thorough peer review by experienced researchers in your field

- rapid publication on acceptance

- support for research data, including large and complex data types

- gold Open Access which fosters wider collaboration and increased citations

- maximum visibility for your research: over $100 \mathrm{M}$ website views per year

At BMC, research is always in progress.

Learn more biomedcentral.com/submissions 